\title{
Hot and cool executive functions in very and extremely preterm preschool children
}

\begin{abstract}
BACKGROUND
In most countries, premature deliveries constitute $5 \%$ to $18 \%$ of births. Some preterm children, especially those born before 32 weeks of pregnancy, experience serious medical complications, which can affect their subsequent development and functioning. Even those who have an IQ within the normal range can be at risk of worse functioning. This study aimed to investigate the differences in development of hot and cool aspects of executive functions in children born prematurely in comparison to those born on time. It is also focused on evaluating relationships between executive functions in premature children and their socio-emotional competences.
\end{abstract}

PARTICIPANTS AND PROCEDURE

All children participating in the study were preschoolers. The sample consisted of 20 children born before 32 weeks of gestation and 28 term controls (children born on time). Hot and cool aspects of executive functions were examined in both groups using tasks extracted from the Preschool Self-Regulation Assessment (PSRA). Parents of children born prematurely also completed the Strengths and Difficulties Questionnaire (SDQ), which is a brief behavioral screening questionnaire that consists of five scales: emo- tional symptoms, conduct problems, hyperactivity/inattention, peer relationship problems and prosocial behavior.

\section{RESULTS}

Premature children scored lower for both hot and cool executive functions in comparison to the children born at term in two of the five tasks. In addition, an association between worse executive functioning and more severe problems was found in the preterm group. This link applies to both general and specific problems, such as hyperactivity/ inattention and behavioral problems.

\section{CONCLUSIONS}

Prematurely born children may have larger deficits both in hot and cool aspects of executive functions compared to their peers born at term. Deficits in hot aspect may be reflected in hyperactivity/inattention symptoms and conduct problems, whereas difficulties in cool aspect may be more related to the general picture of problems in prematurely born children.

\section{KEY WORDS}

executive functions; preterm birth; preschool aged children; cognitive functioning; preschoolers

ORgANIZATION - Institute of Psychology, University of Gdansk, Gdansk, Poland

AUthors' CONTRiButions - A: Study design - B: Data collection - C: Statistical analysis - D: Data interpretation .

E: Manuscript preparation · F: Literature search · G: Funds collection

CORRESPONDING AUthor - Tamara Zofia Walczak, Institute of Psychology, University of Gdansk, 4 Jana Bażyńskiego Str., 80-309 Gdańsk, Poland, e-mail: walczak.tamara@gmail.com

To CITE THIS ARTICLE - Walczak, T. Z., \& Chrzan-Dętkoś, M. (2018). Hot and cool executive functions in very

and extremely preterm preschool children. Health Psychology Report, 6(1), 40-49. doi: https://doi.org/10.5114/

hpr.2018.71436

RECEIVED 19.05.2017 · REVIEWED 11.07.2017 · ACCEPTED 06.10.2017 · PUBLISHED 22.11.2017 


\section{BACKGROUND}

According to the World Health Organization Expert Group on Prematurity (WHO, 1950), birth occurring $<37$ completed weeks of gestation, after the onset of the maternal last menstrual period (LMP), is defined as preterm birth. The following subgroups of premature infants are distinguished: 'extremely preterm' refers to those born $<28$ weeks, 'very preterm' is used to describe infants born $<32$ weeks, 'moderately preterm' describes those between 32 and $33+6$ weeks and 'late preterm' is a category referring to children born between 34 and $36+6$ weeks (Raju, Higgins, Stark, \& Leveno, 2006; Shapiro-Mendoza \& Lackritz, 2012). WHO reports (2015) indicate that the rate of preterm birth, across 184 countries, ranges from $5 \%$ to $18 \%$ of babies born. Every year, an estimated 15 million babies are born preterm - that is, more than 1 in 10 babies.

Although in the last 20 years the survival rate of premature babies has increased, alongside their chances for normal development (due to advances in technologies in medicine) (interview with neonatologist Ewa Helwich; Rokita, 2017), children born very early, or with a very low birth weight, are at risk of serious neurodevelopmental difficulties such as cerebral palsy, pervasive developmental disorder, and general learning disability (Poehlmann et al., 2011; Wolke, 2010; Pritchard et al., 2009). Beside neurodevelopmental impairments (e.g. hearing, visual and motor disabilities), premature birth can result in reduced cognitive capacity, learning disabilities, poor academic outcomes and social and behavioral difficulties (Wolke, 2010; Poehlmann et al., 2011). Very or extremely prematurely born (preschool- and schoolaged) children are $50 \%$ more likely than full-term children to have behavioral difficulties in the clinical range (Reijneveld et al., 2006). It is worth adding that even prematurely born children who are not affected by neurodevelopmental impairments (and have an IQ within the normal range) are at risk of worse school performance than children born at term (Marlow, Wolke, Bracewell, \& Samara, 2005; Lee, Yeatman, Luna, \& Feldman, 2011).

The brains of preterm children, compared to infants born at term, mature and form under relatively adverse conditions: the mass of the brain of a child born in the 34 th week of pregnancy is only $65 \%$ of the weight of the brain of a child born in the $40^{\text {th }}$ week of pregnancy (Kinney, 2006). Smaller brain volume impacts on verbal performance and IQ scores at school age and in adolescence is often associated with poorer neurodevelopmental outcomes (Skiöld, 2011). Researchers suggest that problems with concentration, which can continue on into adulthood, are the most common consequences of the immaturity of the brain at birth (Aarnoudse-Moens, Smidts, Oos- terlaan, Duivenvoorden, \& Weisglas-Kuperus, 2009; Anderson, 2014; Bhutta, Cleves, Casey, Cradock, \& Anand, 2002; Hack et al., 2009; Mulder, Pitchford, Hagger, \& Marlow, 2009; Johnson \& Marlow, 2011). Johnson and Marlow (2011), in their review of research on the most common problems in premature children, described a pattern of behavior that they defined as phenotypic. This pattern is characterized by an increased risk of symptoms related to difficulties in concentration, anxiety, and social functioning.

Although the problems of prematurity are relatively well described in the literature, there is a lack of information about the early onset of the child's difficulties with cognitive and social functioning. For preterms, the preschool period is a time of remediation for some developmental delays. On the other hand, it is also a time when some difficulties become visible and can be diagnosed. Between 2 and 5 years of age, important changes occur in executive functions (EF) (Zelazo \& Müller, 2010). This "umbrella" construct refers to many processes involved in the conscious control of thought and action, and has long been associated with the consequences of prefrontal cortex (PFC) damage. There are some definitional issues around the construct of EF. Many concepts exist that distinguish different aspects of executive functions. Sometimes it is only one aspect of EF, such as inhibitory control in for instance Barkley's (1997) and Dempster's (1992) theories, but others involve more aspects, such as Miyake et al. (2000), who distinguish three aspects of EF: inhibition (of prepotent responses), cognitive flexibility and working memory (updating and monitoring of representations). The problem, however, pointed out by Zelazo and Müller (2010) is that many of the tasks that were designed to measure one specific aspect of EF can, in fact, overlap with other aspects and processes. These researchers (Zelazo \& Müller, 2010, pp. 576-577) claimed that "providing labels for factors may lead to the impression that researchers understand the cognitive processes underlying performance on various tasks, but this is rarely the case ... the same tasks are sometimes clustered with different tasks, and characterized by different labels".

An alternative approach that goes beyond these limitations was presented by Zelazo, Carter, Reznick and Frye (1997). Their idea, based on Luria's concept of interactive functional systems (1973), emphasizes that EF is a function, not a cognitive structure or a mechanism. Functions are behavioral constructs determined by their results - what they achieve. Thus, for executive functioning the outcome is thoughtful problem solving. Therefore it is possible to distinguish functional phases organized around the constant outcome of solving a problem: problem representation, planning, execution (intending/rule use) and evaluation (error detection/correction) (Zelazo et al., 1997). What actually really matters is the extent
Hot and cool executive functions in preterm preschoolers 
Tamara Zofia

Walczak,

Magdalena

Chrzan-Dętkoś to which EF involve the regulation of affect and motivation. Though executive functions are considered in mainly domain-general terms, researchers (Zelazo \& Müller, 2010) distinguish relatively "cool" aspect of EF associated with the lateral prefrontal cortex (L-PFC) and relatively "hot" aspect of EF associated with the ventral and medial prefrontal cortex (VM$\mathrm{PFC})$. Cool $\mathrm{EF}$ is required in more abstract, decontextualized situations, whereas hot EF is more likely characterized by high affective involvement or when a flexible assessment of the affective significance of a stimulus is required. From a neuroanatomical perspective this distinction makes considerable sense, e.g. VM-PFC connects firmly and directly with the limbic system, while L-PFC connections are partly mediated by the orbitofrontal cortex (OFC) (Zelazo \& Müller, 2010). Nevertheless, as one should remember, they are part of the same system and work together in the normal case.

It is probably impossible to create tasks that would purely measure hot or cool EF, although it is possible to create tasks that emphasize one or the other aspect of EF. A common tool for assessing cool aspect of executive functions is Dimensional Change Card Sort (DCCS; Zelazo, 2006), where the subject's task is to sort cards according to the rule given. To assess hot aspect of EF Kerr and Zelazo (2004) designed the Children's Gambling Task, in which the subject must learn to select cards from the set, which leads to a more beneficial final result. In contrast to these relatively complex measures Brock, Rimm-Kaufman, Nathanson and Grimm (2009) extracted six relatively simple tasks from the Preschool Self-Regulation Assessment (PSRA) that measure hot (tasks: toy sort, toy wrap and toy wait) aspect of EF and cool (tasks: balance beam and pencil tap) aspect of EF in small children.

Much of the research emphasizes the association between deficits in cool aspect of EF with lower behavior regulation skills (Cole, Usher, \& Cargo, 1993; McGlamery, Ball, Henley, \& Besozzi, 2007). Castellanos and colleagues (2006) found that deficits in cool aspect of EF are associated with inattention symptoms, whereas deficits in hot aspect of EF are reflected in hyperactivity/impulsivity symptoms. Research by Andrews-Espy, Sheffield, Wiebe, Clark, and Moehr (2011) confirmed the link between executive control deficits and disinhibition, reduced ability to regulate emotions, attention disorders, and hyperactivity. Studies indicate that the level of development of executive functions is essential for a child's school readiness (Brock et al., 2009). To a large extent, it determines not only the educational success (Biederman et al., 2004; Yeniad, Malda, Mesman, van IJzendoorn, \& Pieper, 2013), but also functioning in adulthood, career, even health (a review of research by Diamond \& Lee, 2011). EF difficulties can intensify with age associated with increasing educational support needs (Wolke, 2010; Reijneveld et al., 2006).
From what we know, there is a lack of research that tested the executive functions in preterm children in the above-discussed hot and cool approach. Marlow, Hennessy, Bracewell and Wolke (2007) pointed out the difficulties in the areas of planning, self-regulation, visual search accuracy, inhibition and motor persistence in a large study of extremely preterm school-age children. Mulder et al. (2009) conducted a meta-analysis and confirmed that executive functions and attention are areas of weakness in preterm children. Aarnoudse-Moens et al. (2009) showed that very preterm children $(\leq 30$ weeks gestation) have impairments in executive function independent of IQ and processing speed at early school age. These conclusions are also confirmed by Aarnoudse-Moens, Duivenvoorden, Weisglas-Kuperus, Van Goudoever, and Oosterlaan (2012), who found that very preterm children catch up with their peers in response inhibition, but remain behind in neurocognitive functions such as fluency, planning, and working memory. However, little is known about the differences in the cool and hot aspects of executive functions between premature children and their term-born peers. It remains unknown how these two aspects of executive functions are related to the socio-emotional difficulties of premature children. Providing information about performance in those aspects may serve as a starting point in further seeking the neuronal causes of such differentiation and for tracing developmental trajectories.

In developmental psychology, the preschool period is an important moment for development of the competencies that are the basis for later school education - executive functions. Thus the main goal of this study was to evaluate the development of hot and cool executive functions and its associations with the socio-emotional development of preschool-aged children born very prematurely.

Based on previous findings and for the purpose of this study, the following hypotheses were formulated:

1. Children born very prematurely perform worse in tasks assessing hot and cool aspects of executive function compared to children born at term.

2. Lower scores in tasks measuring executive functions in children born very prematurely are associated with a higher intensity of behavioral problems and hyperactivity/inattention.

\section{PARTICIPANTS AND PROCEDURE}

\section{SAMPLE}

Foundations, kindergartens and support groups for premature parents helped in recruiting children to the study. The exclusion criteria included severe birth defects and motor disability that prevented the 
child from moving freely. A sample of 20 very and extremely preterm (<32 weeks gestation) children and 28 term controls participated. Preterm children ranged in age from 36 to 71 months $(M=51.55$, $S D=11.90)$. The mean gestational age was 29.50 weeks, the median was 30.00 , the minimum was 26 and the maximum was 31 weeks. The birth weight ranged from $600 \mathrm{~g}$ to $1740 \mathrm{~g}$, mean $1169.22 \mathrm{~g}$ and median $1167.50 \mathrm{~g}$. Although medical information was not included in the analysis, because of the small test group and the inability to make further divisions, the discharge documentation from the hospital and interviews with parents included information on central nervous system (CNS) infusions in 7 children, retinopathy of prematurity (ROP) in 6 children, infant respiratory distress syndrome (IRDS) in 9 children and anemia in 11 children. In addition, hospital records included information on brain cysts in 3 children. Nineteen of 20 children in this group were attending public or private kindergarten. Girls were in the majority in this group $(60.00 \%)$.

The research was conducted at the Institute of Psychology at the University of Gdansk in 2015-2016. The study room was equipped with a Venetian mirror (with child and researcher on one side and the parent on the other side). After each task, the child had the opportunity to take a break if feeling tired. The characteristics of the tasks can be found in the measurement section. While the children participated in several tasks measuring executive functions, the mothers were asked to complete the Strengths and Difficulties Questionnaire (SDQ).
Term controls ranged in age from 36 to 70 months $(M=51.00, S D=11.50)$. In this group, $57.10 \%$ were girls. The research was conducted in a public kindergarten with the consent of the children, teachers, parents, and principal. Tasks were performed in a research room supervised by a nursery worker. The procedure looked identical to that of the premature group.

\section{MEASUREMENT}

\section{Executive functions}

Hot and cool executive functions were measured with the Preschool Self-Regulation Assessment (PSRA). The PSRA was adapted from a series of lab-based tasks for use in field contexts (such as preschool) by Radiah Smith-Donald, Cybele Raver, Tiffany Hayes, and Breeze Richardson (2007). The PSRA was designed to assess self-regulation in emotional, attentional, and behavioral domains by using a brief, structured battery of tasks. It was found that six tasks from the PSRA are good methods for measuring executive functions in young children. The characteristics of these tasks can be found in Table 1 . The pencil tap and balance beam tasks were used to measure the cool aspect of executive functions. The hot aspect were assessed with the toy sort, toy wrap, and toy wait tasks (Brock et al., 2009). Although Brock and colleagues (2009) confirmed that a two-factor model is a better fit than a conventional approach of a one-factor model

Table 1

Characteristics of tasks measuring executive functions from the Preschool Self-Regulation Assessment (PSRA) (Smith-Donald et al., 2007)

\begin{tabular}{|c|c|c|c|}
\hline Task & Description & $\begin{array}{l}\text { Measurement } \\
\text { method }\end{array}$ & $\begin{array}{l}\text { Aspect of executive } \\
\text { functioning }\end{array}$ \\
\hline Balance beam & $\begin{array}{l}\text { After walking along a line once, the } \\
\text { child was directed to walk the same } \\
\text { line slowly }\end{array}$ & $\begin{array}{l}\text { Difference between } \\
\text { slow and regular } \\
\text { trials (s) }\end{array}$ & COOL \\
\hline Pencil tap & $\begin{array}{l}\text { The child was asked to tap once } \\
\text { when the assessor tapped twice, and } \\
\text { tap twice when the assessor tapped } \\
\text { once }\end{array}$ & $\begin{array}{l}\text { Amount of correct } \\
\text { responses }\end{array}$ & COOL \\
\hline Toy sort & $\begin{array}{c}\text { The child was asked to sort and put } \\
\text { away small toys without playing with } \\
\text { them }\end{array}$ & $\begin{array}{l}\text { Latency to complete } \\
\text { clean up (s) }\end{array}$ & HOT \\
\hline Toy wrap & $\begin{array}{c}\text { The child was asked not to peek } \\
\text { while the assessor noisily wrapped } \\
\text { a "surprise" }\end{array}$ & $\begin{array}{l}\text { Latency to first peek } \\
\qquad(\mathrm{s})\end{array}$ & HOT \\
\hline Toy wait & $\begin{array}{l}\text { The child was directed to wait with- } \\
\text { out touching the wrapped "surprise" }\end{array}$ & $\begin{array}{l}\text { Latency to touch } \\
\text { surprise (s) }\end{array}$ & HOT \\
\hline
\end{tabular}

Hot and cool executive functions in preterm preschoolers 
Tamara Zofia

Walczak,

Magdalena Chrzan-Dętkoś composed of all EF variables (i.e., balance beam, pencil tap, toy sort, toy wrap and toy wait), in our study no factor analysis was performed and we decided to analyze the individual tasks and refer them to a problem-solving framework (Zelazo et al., 1997). Raters in the research by Brock et al. (2009) administered the tasks during a piloting phase of the battery and dual coded them to collect reliability data. The intraclass correlation coefficient between the two raters (twoway random model) across nine children equaled .99.

In the pencil tap task, the measurement is the number of correct responses. In the balance beam task, the measurement is the difference between slow and regular trials (the bigger the difference, the better the result). In the toy sort task, the measurement is the time to complete clean up (the shorter the time, the better the result). In the toy wrap and toy wait tasks, the time to first peek and touch is measured (the longer, the better).

\section{Problems/difficulties of the children}

The Strengths and Difficulties Questionnaire (SDQ) by Goodman and Goodman (2009) (Polish version by Davey, Cieciuch, Maćkiewicz, Najderska and Skoczeń) was used to measure the problems and difficulties of the preterm children. This brief behavioral screening questionnaire consists of 25 items which are divided into 5 scales: emotional symptoms, conduct problems, hyperactivity/inattention, peer relationship problems, and prosocial behavior. Individual scales consist of five statements, where parents determine, on a 3-point scale, the extent to which the statement fits the description of their child (" 0 " means a completely inaccurate description of the child, while " 2 " indicates a completely accurate description). Reliability analysis (Cronbach's $\alpha$ ): emotional symptoms: $\alpha=.68$, conduct problems: $\alpha=.52$, hyperactivity/ inattention: $\alpha=.67$, peer relationship problems: $\alpha=.65$, prosocial behavior: $\alpha=.71$. The diagnostic significance of this tool is dependent on the type of disorder or problem. The best recognition (as much as $70-90 \%$ ) occurs for the following disorders: attention deficit hyperactivity disorder, oppositional de- fiant disorder, depression, pervasive developmental disorder, and some anxiety disorders. There is worse recognition (up to 30-50\%) for: specific phobias, panic disorder, agoraphobia, eating disorders, and separation anxiety (Goodman, Ford, Simmons, Gatward, \& Meltzer, 2000). Access to the questionnaire can be obtained via the website: http://www.sdqinfo.com/.

\section{RESULTS}

Statistical calculations were performed using IBM SPSS for Windows. Student's t-tests and regression analyses were performed, followed by Pearson correlation.

Hypothesis 1: Children born very prematurely perform worse in tasks assessing hot and cool aspects of executive function compared to children born at term.

Table 2 summarizes the results obtained by children in the PSRA. In order to verify the differences between the group of children born prematurely and the group of children born at term, Student's $t$-test was performed.

For executive functions, statistically significant differences occurred in the pencil tap $(p=.010)$ and toy sort $(p=.050)$ tasks. Children born prematurely performed worse in the pencil tap $(M=9.15$, $S D=6.16)$ and toy $\operatorname{sort}(M=110.20 \mathrm{~s}, S D=19.42)$ tasks, compared to term controls (pencil tap: $M=13.36$, $S D=2.83$; toy sort: $M=91.96 \mathrm{~s}, S D=27.42)$. Other results were not significant, but showed a similar tendency (lower performing by the group of prematurely born children).

Hypothesis 2: Lower scores in tasks measuring executive functions in children born very prematurely are associated with higher intensity of behavioral problems and hyperactivity/inattention.

The results of the Strengths and Difficulties Questionnaire (SDQ), in the group of preterm children, were compared to the categories and cut-off points identified by the authors of the questionnaire (Goodman \& Goodman, 2009). The results of emotional symptoms, conduct problems, prosocial behavior, and the total score of difficulties are close to the average for this

Table 2

Comparison of the results obtained in the PSRA (executive functions) by preterm children and term controls

\begin{tabular}{lcccccccccc}
\hline \multirow{2}{*}{ Task } & \multicolumn{3}{c}{ Term controls } & \multicolumn{3}{c}{ Preterm children } & \multicolumn{4}{c}{$t$-test } \\
\cline { 2 - 12 } & $M$ & $S D$ & $N$ & $M$ & $S D$ & $N$ & $t$ & $d f$ & $p$ & $d$ \\
\hline Balance beam & $2.52 \mathrm{~s}$ & 4.49 & 28 & $1.07 \mathrm{~s}$ & 4.32 & 20 & 1.12 & 46 & .270 & 0.38 \\
Pencil tap & 13.36 & 2.83 & 28 & 9.15 & 6.16 & 20 & 2.85 & 46 & .010 & 1.51 \\
Toy sort & $91.96 \mathrm{~s}$ & 27.42 & 28 & $110.20 \mathrm{~s}$ & 19.42 & 20 & -2.70 & 46 & .010 & -0.83 \\
Toy wrap & $41.18 \mathrm{~s}$ & 25.88 & 28 & $32.10 \mathrm{~s}$ & 25.07 & 20 & 1.21 & 46 & .230 & 0.44 \\
Toy wait & $60.00 \mathrm{~s}$ & 0.00 & 28 & $54.55 \mathrm{~s}$ & 16.84 & 20 & 1.45 & 46 & .160 & 1.99 \\
\hline
\end{tabular}


age group. The results for the hyperactivity/inattention $(M=5.10, S D=2.34)$ and peer relationship problems $(M=2.60, S D=2.20)$ factors are elevated in comparison to the average results for this age group, but do not exceed the cut-off point for the clinical group.

Table 3 shows the correlation between results in executive functions, measured by the PSRA, with the most common problems from the Strengths and Difficulties Questionnaire (SDQ).

The correlations between executive functions and occurring problems indicate the relationship between intensification of general socio-emotional problems and lower performance in cool executive functions - measured by the pencil tap $(r=-.46)$ task. Hyperactivity/inattention and conduct problems correlate with poorer functioning in hot executive functions - measured by the toy sort $(r=.48)$ and toy wait $(r=-.58)$ tasks.

Subsequent single-variable regression analyses were performed to check whether the performances in these tasks act as predictors of socio-emotional functioning of premature children. The regression analysis indicated that the cool executive functions measured by the pencil tap task explained $21 \%$ of the variance of the overall result of difficulties $\left(R^{2}=.21, F(1,18)=4.80, p=.040\right)$. Based on the regression coefficients it can be stated that the higher development of cool aspect of executive functions, as measured by the pencil tap, is associated with less severe general difficulties in premature children $(\beta=-.46$, $p=.010$ ). Hot executive functions measured by the toy sort task explain $23 \%$ of variance of conduct problems $\left(R^{2}=.23, F(1,18)=5.47, p=.030\right)$, whereas measured by the toy wait task explain $34 \%$ of variance of hyperactivity/inattention $\left(R^{2}=.34, F(1,18)=9.15\right.$, $p=.010)$. Thus, lower hot executive functions, as measured by toy sort, are associated with more severe behavioral problems $(\beta=.48, p=.030)$ and measured by toy wait task are associated with greater inattention and hyperactivity $(\beta=-.58, p=.010)$.

\section{DISCUSSION}

The present study offers general insight into executive functions of preschool-aged children born prematurely, in the hot and cool approach. The major finding that emerged from the study is that premature children showed lower performance, compared to children born on time, in both aspects of EF at the level of significance or a tendency.

Significant difference in the performance of the pencil tap task may point to difficulties in behavioral inhibition that involves the suppression of a prepotent response (Friedman \& Miyake, 2004). This task, in which children were presented with a pair of ad hoc rules - "Tap twice when I tap once. Tap once when I tap twice." - and then asked to use these rules, initially in 6 practice trials and then in 16 assessed trials, investigate rule use ("execution" in Zelazo, Carter, Reznick, and Frye problem-solving framework, 1997). Analyses of errors revealed a tendency to repeat responses after researcher. So despite the fact that children seemed to understand the task and the rules, and actually started to use them, they were susceptible to make this kind of error. The pencil tap seems to be also a more demanding task and requires attention and working memory abilities more than balance beam task. Thus, attentional problems in preterms may underlie the performance in cool aspect of EF.

Motivational significance to a rule use was added in the toy sort task. A significant difference in the performance of this task may indicate difficulties in inhibiting the tendency to play with the toys. Prematurely born children have difficulty implementing the simple rules for the purpose of the task due to the attractiveness of the stimulus (they start to sort properly but after a while they start playing with the toys). This task, measuring hot aspect of EF, also investigate rule use ("execution" in the Zelazo et al. problem-solving framework, 1997).

\section{Table 3}

Correlation (Pearson's r) between the results of PSRA (executive functions) and the results of Strengths and Difficulties Questionnaire (SDQ) in preterm group

\begin{tabular}{lcccccc}
\hline Task & \multicolumn{5}{c}{ SDQ } \\
\cline { 2 - 7 } & $\begin{array}{c}\text { Emotional } \\
\text { symptoms }\end{array}$ & $\begin{array}{c}\text { Conduct } \\
\text { problems }\end{array}$ & $\begin{array}{c}\text { Hyperactivity/ } \\
\text { inattention }\end{array}$ & $\begin{array}{c}\text { Peer } \\
\text { relationship } \\
\text { problems }\end{array}$ & $\begin{array}{c}\text { Prosocial } \\
\text { behavior }\end{array}$ & $\begin{array}{c}\text { Overall } \\
\text { result of } \\
\text { difficulties }\end{array}$ \\
\hline Balance beam & -.35 & -.09 & -.31 & -.37 & .01 & -.43 \\
Pencil tap & -.06 & -.37 & -.39 & -.44 & .33 & $-.46^{*}$ \\
Toy sort & -.15 & $.48^{*}$ & .13 & .15 & -.08 & .20 \\
Toy wrap & -.09 & -.25 & -.41 & -.32 & .33 & -.41 \\
Toy wait & .00 & -.29 & $-.58^{* *}$ & -.06 & .24 & -.35 \\
\hline
\end{tabular}

Note. ${ }^{*} p<.05,{ }^{* *} p<.01$.

Hot and cool executive functions in preterm preschoolers 
Tamara Zofia

Walczak,

Magdalena

Chrzan-Dętkoś
Differences in other tasks - toy wrap and toy wait - were not significant, but showed a tendency to lower performance in hot aspect of EF (both tasks investigate rule use) by premature children. Both tasks are examples of a classic paradigm of delay of gratification. The results indicate that these children may have particular difficulty regulating behavior in motivationally significant situations. However, this needs to be confirmed in further research.

The differences in the balance beam task was also not significant, but showed a tendency to lower performance in cool aspect of EF by premature children. This task also investigate rule use, and lower performance may indicate difficulties with inhibiting prepotent behavioral response. Yet further research is also needed here to confirm this tendency.

In addition, the relationship between the executive functions and the severity of other difficulties in preterm children was investigated and point to the most potent compound between child's ability to delay gratification (measured by the toy wait task) and intensity of hyperactivity/inattention. This is partly confirmed in research by Castellanos and colleagues (2006), in which deficits in hot aspect of EF were reflected in hyperactivity/impulsivity symptoms. A statistically significant relationship was found between another hot aspect of EF (rule use measured by toy sort task) and intensity of conduct problems. The results are consistent with other studies which also confirmed the relationship between executive functions and behavior problems in children; e.g. Hughes, Dunn and White (1998) showed that difficulties with working memory, cognitive flexibility, inhibitory control, and the ability to create plans correlate with the perception of children as behaviorally difficult by their parents. Research by Andrews-Espy et al. (2011) confirmed the link between executive control deficits and disinhibition, reduced ability to regulate emotions, attention disorders, and hyperactivity.

The study also showed that behavioral inhibition corresponding to cool aspect of EF (and measured by the pencil tap task) is associated with overall intensity of difficulties. This association is also apparent in the case of the balance beam task, which also corresponds to cool aspect of EF. This may indicate that difficulties in cool aspect of EF are more related to the general picture of problems in the child than difficulties in hot aspect, but this requires further investigations.

Deficits in regulation of emotions and problems in situations requiring adaptation to changing social conditions are frequently observed in premature children (Elgen et al., 2012; Reijneveld et al., 2006; Skiöld, 2011; Wolke, 2010). With high probability, as children get older, emotional and behavioral problems may affect academic functioning (Reijneveld et al., 2006; Wolke, 2010). It therefore seems necessary to identify their health and educational needs.
Responsive and sensitive parents' and teachers' practices can ameliorate disadvantages, e.g. Woythaler and colleagues (2011) believe that lack of support in childhood is associated with detrimental life outcomes for people (born prematurely) - school underachievement, unemployment, poor psychological and social well-being. Salonen, Lepola and Vauras (2007) indicate the importance of parenting practices for a child's problem-solving skills and academic achievements. Moreover, it is thought that parenting practices are of great importance for the socio-emotional and motivational development. Research (Lucassen et al., 2015) showed that the environment in which the child develops (including the style of parenting) influences the development of the prefrontal cortex and thus affects the development of executive functions. Research also indicates that parents of premature babies are often overprotective and see fewer strengths in the child than parents of children born at term. This tendency towards both overprotection and underestimation is particularly evident in the parents of children born before 32 weeks of pregnancy (Chrzan-Dętkoś \& Karasiewicz, 2014; Chrzan-Dętkoś, 2012). Thus, premature children can be at risk of impairment in the development of executive functions due to both unfavorable biological and environmental factors.

It is important to realize that not all parent-child interactions contribute to the development of executive functions. It is necessary to create conditions in which a child has a sense of understanding and support. It should be emphasized that for developing executive functions, self-regulation, and emotional regulation, parents and teachers should assign challenges, not tasks (which may be perceived as a threat by the child). Parents and teachers can help develop executive functions by encouraging the child to explore and think creatively (Brzezińska \& Nowotnik, 2012; Wygotski, 1971).

The greatest limitation of the present study is the small test group. It did not allow us to make further divisions, for instance into subgroups, due to medical risk. It seems important to assess whether medical risk can be a predictor of executive functions in children born prematurely. The role of early medical complications such as central nervous system (CNS) infusions, periventricular leukomalacia (PVL), retinopathy of prematurity (ROP) and infant respiratory distress syndrome (IRDS) should be taken into consideration in subsequent analyses. Further studies should also compare the social and emotional difficulties within the group of preterm children and make a comparison to their peers born at term. Also further investigation may be useful in order to collect data from teachers rather than parents.

The results presented in this paper indicate a strong need for further investigations and explorations in the field of executive functions in premature 
children. The influence and relevance of biological factors (including early brain damage) and psychological factors (including parental attitudes) should be considered. The functioning of the mothers of premature babies and its connection with the executive functions of their children should also be considered. It would be interesting to conduct an experiment in which premature children would be subjected to therapeutic interventions, targeted at supporting the development of executive functions. The results of such a study could be the basis for creating therapeutic and educational programs, and help working with prematurely born children at home and at school.

\section{CONCLUSIONS}

- Prematurely born children may have larger deficits both in hot and cool aspects of executive functions compared to their peers born at term, measured during the preschool period.

- Difficulties in executive functions in preschool-aged prematurely born children may be related to observed social and emotional problems.

- Deficits in hot aspect of EF may be reflected in hyperactivity/inattention symptoms and conduct problems in prematurely born children.

- Difficulties in cool aspect of EF may be more related to the general picture of problems in the prematurely born children than difficulties in hot aspect.

\section{REFERENCES}

Aarnoudse-Moens, C. S., Duivenvoorden, H. J., Weisglas-Kuperus, N., Van Goudoever, J. B., \& Oosterlaan, J. (2012). The profile of executive function in very preterm children at 4 to 12 years. Developmental Medicine \& Child Neurology, 54, 247-253.

Aarnoudse-Moens, C. S. H., Smidts, D. P., Oosterlaan, J., Duivenvoorden, H. J., \& Weisglas-Kuperus, N. (2009). Executive function in very preterm children at early school age. Journal of Abnormal Child Psychology, 37, 981-993. doi: 10.1007/ S10802-009-9327-Z19488851

Anderson, P. J. (2014). Neuropsychological outcomes of children born very preterm. Seminars in Fetal and Neonatal Medicine, 19, 90-96. doi: 10.1016/J. Siny.2013.11.012

Andrews-Espy, K., Sheffield, T. D., Wiebe, S. A., Clark, C. A. C., \& Moehr, M. J. (2011). Executive control and dimensions of problem behaviors in preschool children. Journal of Child Psychology and Psychiatry, 52, 33-46.

Barkley, R. A. (1997). Behavioral inhibition, sustained attention, and executive functions: constructing a unifying theory of ADHD. Psychological Bulletin, 121, 65-94.
Biederman, J., Monuteaux, M. C., Doyle, A. E., Seidman, L. J., Wilens, T. E., \& Ferrero, F. (2004). Impact of executive function deficits and attention-deficit/hyperactivity disorder (ADHD) on academic outcomes in children. Journal of Consulting and Clinical Psychology, 72, 757-766.

Bhutta, A.T., Cleves, M.A., Casey, P.H., Cradock, M.M., \& Anand, K. J. (2002). Cognitive and behavioral outcomes of school-aged children who were born preterm: a meta-analysis. Journal of the American Medical Association, 288, 728-737. doi: 10.1001/ jama.288.6.72812169077

Brock, L. L., Rimm-Kaufman, S. E., Nathanson, L., \& Grimm, K. J. (2009). The contributions of 'hot' and 'cool' executive functions to children's academic achievements, learning-related behaviors, and engagement in kindergarten. Early Childhood Research Quarterly, 24, 337-349.

Brzezińska, A. I., \& Nowotnik, A. (2012). Funkcje wykonawcze a funkcjonowanie dziecka w środowisku przedszkolnym i szkolnym [Executive functions and the functioning of a child in the preschool and school environment]. Edukacja, 1, 61-74.

Castellanos, F. X., Sonuga-Barke, E. J., Milham, M. P., \& Tannock, R. (2006). Characterizing cognition in ADHD: beyond executive dysfunction. Trends in cognitive sciences, 10, 117-123.

Chrzan-Dętkoś, M., \& Karasiewicz, K. (2014). Mother's perception of preterm preschoolers in a sample of Polish women. Journal of Reproductive and Infant Psychology, 32, 270-281. doi: 10.1080/02646838.2013.879567

Chrzan-Dętkoś, M. (2012). Wcześniaki. Rozwój psychoruchowy w pierwszych latach życia [Premature children. Psychomotor development in the first years of life]. Gdańsk: Harmonia Universalis.

Cole, P. M., Usher, B. A., \& Cargo, A. P. (1993). Cognitive risk and its association with risk for disruptive behavior disorder in preschoolers. Journal of Clinical Child Psychology, 22, 154-164.

Dempster, F. N. (1992). The rise and fall of the inhibitory mechanism: Toward a unified theory of cognitive development and aging. Developmental review, 12, 45-75.

Diamond, A., \& Lee, K. (2011). Interventions shown to aid executive function development in children 4-12 years old. Science, 333, 959-964.

Elgen, S. K., Leversen, K. T., Grundt, J. H., Hurum, J., Sundby, A. B., Elgen, I. B., \& Markestad, T. (2012). Mental health at 5 years among children born extremely preterm: a national population-based study. European Child and Adolescent Psychiatry, 21, 583-589.

Friedman, N. P., \& Miyake, A. (2004). The relations among inhibition and interference control functions: a latent-variable analysis. Journal of experimental psychology: General, 133, 101-135.
Hot and cool executive functions in preterm preschoolers 
Goodman, R., Ford, T., Simmons, H., Gatward, R. \& Meltzer, H. (2000). Using the Strengths and Difficulties Questionnaire (SDQ) to screen for child psychiatric disorders in a community sample. The British Journal of Psychiatry, 177, 534-539.

Goodman, A., \& Goodman, R. (2009). Strengths and Difficulties Questionnaire as a Dimensional Measure of Child Mental Health. Journal of the American Academy of Child and Adolescent Psychiatry, 48, 400-403.

Tamara Zofia Walczak, Magdalena Chrzan-Dętkoś
Hack, M., Taylor, H. G., Schluchter, M., Andreias, L., Drotar, D., \& Klein, N. (2009). Behavioral outcomes of extremely low birth weight children at age 8 years. Journal of Developmental \& Behavioral Pediatrics, 30, 122-130. doi: 10.1097/ DBP.0b013e31819e6a1619322106

Hughes, C., Dunn, J., \& White, A. (1998). Trick or treat? Uneven understanding of mind and emotion and executive dysfunction in 'hard-to-manage' preschoolers. Journal of Child Psychology and Psychiatry, 39, 981-994.

Johnson, S., \& Marlow, N. (2011). Preterm birth and childhood psychiatric disorders. Pediatric Research, 69, 11R-18R.

Kerr, A., \& Zelazo, P. D. (2004). Development of "hot" executive function: The children's gambling task. Brain and cognition, 55, 148-157.

Kinney, H. C. (2006). The near-term (late preterm) human brain and risk for periventricular leukomalacia: a review. Seminars in perinatology, 30, 81-88.

Lee, E. S., Yeatman, J. D., Luna, B., \& Feldman, H. M. (2011). Specific language and reading skills in school-aged children and adolescents are associated with prematurity after controlling for IQ. Neuropsychologia, 49, 906-913.

Lucassen, N., Kok, R., Bakermans-Kranenburg, M. J., Van IJzendoorn, M. H., Jaddoe, V. W., Hofman, A., ...Tiemeier, H. (2015). Executive functions in early childhood: The role of maternal and paternal parenting practices. British Journal of Developmental Psychology, 33, 489-505.

Luria, A. R. (1973). The working brain: An introduction to neuropsychology. New York: Basic Books.

Marlow, N., Hennessy, E. M., Bracewell, M. A., \& Wolke, D. (2007). Motor and executive function at 6 years of age after extremely preterm birth. Pediatrics, 120, 793-804.

Marlow, N., Wolke, D., Bracewell, M. A., \& Samara, M. (2005). Neurologic and developmental disability at six years of age after extremely preterm birth. The New England Journal of Medicine, 352, 9-19.

McGlamery, M. E., Ball, S. E., Henley,T. B., \& Besozzi, M. (2007). Theory of mind, attention, and executive function in kindergarten boys. Emotional and $\mathrm{Be}-$ havioural Difficulties, 12, 29-47.

Miyake,A.,Friedman, N.P.,Emerson,M.J.,Witzki,A.H., Howerter, A., \& Wager, T. D. (2000). The unity and diversity of executive functions and their contributions to complex "frontal lobe" tasks: A latent variable analysis. Cognitive psychology, 41, 49-100.

Mulder, H., Pitchford, N. J., Hagger, M. S., \& Marlow, N. (2009). Development of Executive Function and Attention in Preterm Children: A Systematic Review. Developmental Neuropsychology, 34, 393-421.

Poehlmann, J., Miller Schwichtenberg, A. J., Shlafer, R. J., Hahn, E., Bianchi, J. P., \& Warner, R. (2011). Emerging self-regulation in toddlers born preterm or low birth weight: differential susceptibility to parenting? Developmental Psychology, 23, 177-193. Pritchard, V. E., Clark, C. A. C., Liberty, K., Champion, P. R., Wilson, K., \& Woodward, L. J. (2009). Early school-based learning difficulties in children born very preterm. Early Human Development, 85, 215-224.

Raju, T. N., Higgins, R. D., Stark, A. R., \& Leveno, K. J. (2006). Optimizing care and outcome for latepreterm (near-term) infants: a summary of the workshop sponsored by the National Institute of Child Health and Human Development. Pediatrics, 118, 1207-1214.

Reijneveld, S. A., de Kleine, M. J. K., van Baar, A. L., Kollée, L. A. A., Verhaak, C. M., Verhulst, F. C., \& Verloove-Vanhorick, S. P. (2006). Behavioural and emotional problems in very preterm and very low birthweight infants at age 5 years. Archive of Diseases in Childhood (Fetal and Neonatal Edition), 91, F423-F428.

Rokita, M. (2017). Neonatolodzy i pediatrzy powinni współpracować [Neonatologists and pediatricians should work together]. Ogólnopolski Przegląd Medyczny, 3, 26-29.

Salonen, P., Lepola, J., \& Vauras, M. (2007). Scaffolding interaction in parent-child dyads: multimodal analysis of parental scaffolding with task and non-task oriented children. European Journal of Psychology of Education, 22, 77-96.

Shapiro-Mendoza, C. K., \& Lackritz, E. M. (2012). Epidemiology of late and moderate preterm birth. Seminars in Fetal and Neonatal Medicine, 17, $120-125$.

Skiöld, B. (2011). Brain imaging and outcome in extremely preterm infants. Institutionen för kvinnors och barns hälsa [Department of Women's and Children's Health].

Smith-Donald, R., Raver, C. C., Hayes, T., \& Richardson, B. (2007). Preliminary construct and concurrent validity of the Preschool Self-Regulation Assessment (PSRA) for field-based research. Early Childhood Research Quarterly, 22, 173-187.

World Health Organization. (2015). WHO recommendations on interventions to improve preterm birth outcomes. Geneva: World Health Organization. Retrieved from: http://www.who.int/mediacentre/ factsheets/fs363/en/ 
World Health Organization. (1950). Expert Group on Prematurity: final report [on a meeting held in] Geneva, 17-21 April 1950. Geneva: World Health Organization.

Wolke, D. (2010). Small beginnings - large impact: development of preterms and implications for early childhood intervention. Presentation to the Complex Learning Difficulties and Disabilities Research Project, Wolverhampton.

Woythaler, M. A., McCormick, M. C., \& Smith, V. C. (2011). Late preterm infants have worse 24-month neurodevelopmental outcomes than term infants. Pediatrics, 127, e622-e629.

Wygotski, L. S. (1971). Wybrane prace psychologiczne [Selected psychological works]. Warszawa: Wydawnictwo Naukowe PWN.

Yeniad, N., Malda, M., Mesman, J., van IJzendoorn, M. H., \& Pieper, S. (2013). Shifting ability predicts math and reading performance in children: A meta-analytical study. Learning and Individual Differences, 23, 1-9.

Zelazo, P. D. (2006). The Dimensional Change Card Sort (DCCS): A method of assessing executive function in children. Nature Protocols, 1, 297.

Zelazo, P. D., Carter, A., Reznick, J. S., \& Frye, D. (1997). Early development of executive function: A problem-solving framework. Review of General Psychology, 1, 198-226.

Zelazo, P. D., \& Müller, U. (2010). Executive function in typical and atypical development. In U. Goswami (ed.), The Wiley-Blackwell Handbook of Childhood Cognitive Development, Second edition (pp. 574-603). Blackwell Publishing. 